\title{
LÍNGUA PORTUGUESA \\ NA ESCOLA: (RE)FAZENDO UM PERCURSO DE FORMAÇÃO
}

Maria Izabel de Bortoli Hentz*

RESUMO: A partir de meados da década de 1980, a tese de que o texto se constitui em unidade de ensino para a aprendizagem de língua é tema recorrente em estudos e em eventos acadêmicocientíficos da área, em documentos oficiais, na formação inicial e continuada de professores. Neste artigo, pretende-se analisar alguns efeitos de cursos de formaçáo continuada na prática docente, com base no planejamento elaborado por uma professora, em três momentos distintos de trabalho com o texto em sala de aula. $\mathrm{O}$ objeto de análise são três atividades representativas da prática pedagógica dessa professora: uma, realizada em contexto anterior à participação em processos de formação continuada e, duas, realizadas em contextos de formação continuada. A análise evidencia significativa mudança no trabalho com a produção de textos na aula de Língua Portuguesa nos três momentos analisados. O que os diferencia é o conceito de texto que a professora assume e a forma de abordálo nas atividades de escrita. $\mathrm{O}$ estudo indica que a formação continuada pode contribuir para a construção de outra realidade para o ensino e a aprendizagem de língua na escola.

Palavras-chave: Formação de professores. Ensino de língua portuguesa. Produçáo de textos.

\footnotetext{
* Universidade Federal de Santa Catarina, Centro de Ciências da Educação, Florianópolis, SC., Brasil. E-mail de contato: mihentz@gmail.com.
} 


\title{
Portuguese language at school: (re)taking a training course
}

\begin{abstract}
From the 1980's decade on, the thesis that the text is a teaching unit for language learning is a recurring theme in academic studies and scientific events of the area, as well as in official documents and in initial and continuing teacher training. This article intends to analyse some of the effects of continuing education courses on the teaching practice, based on the planning elaborated by a teacher in three distinct moments of working with texts in class. The object of analysis is composed by three activities which represent the pedagogical practice of this teacher: one conducted in a context previous to the participation in continuing education programs, and two within contexts of continuing education. The analysis shows a significant change in the work with text production in the Portuguese Language classroom in the three moments analysed. What distinguished them is the concept of text adopted by the teacher and the way of approaching this concept in writing activities. The study indicates that continuing education may contribute for the construction of another reality for teaching and learning languages at school.
\end{abstract}

Keywords: Teacher training. Portuguese language teaching. Text production.

\section{INICIANDO A REFLEXÃO}

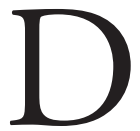

os múltiplos aspectos a partir dos quais é possível analisar o ensino e a aprendizagem de Língua Portuguesa, a reação-resposta de professores no planejamento de suas aulas, como decorrência de sua participação em ações de formação continuada, pode ser um indicativo de como vem se construindo a prática pedagógica para o ensino de língua, particularmente, em relação à produção de textos. ${ }^{1}$

Uma experiência pessoal como formadora em um processo de formaçáo continuada, do qual uma professora participava sistematicamente, provocou alguns questionamentos: em que medida o planejamento das atividades que desenvolve em sala de aula agregou os 
fundamentos que embasam as açôes dos cursos que realiza? O planejamento dela difere fundamentalmente de um momento para outro? A formação continuada responde às necessidades dos professores no que se refere ao trabalho com a produção de textos em sala de aula?

Para responder a estas perguntas, pretende-se analisar, neste artigo, alguns efeitos de cursos de formação continuada na prática docente, com base no planejamento elaborado por uma das professoras participantes. Para este trabalho, foram selecionadas e analisadas três atividades de produção de textos representativas de três momentos distintos de sua prática pedagógica. Uma delas, realizada em contexto anterior a sua participação sistemática em processos de formação continuada e, as outras duas, realizadas quando participava de açóes sistemáticas de formação continuada promovidas pela Secretaria de Educação de um município da Grande Florianópolis, a qual estava vinculada.

O processo de formação se desenvolveu em cinco etapas, nos anos de 1999, 2000, 2001, 2002 e 2007, com vistas à elaboração de uma proposta curricular específica para rede de ensino deste município. Em todas as etapas ${ }^{2}$, o trabalho foi metodologicamente organizado com base em três momentos: reflexão teórica sobre o processo de ensino e aprendizagem de modo amplo, e da língua em particular, a partir da perspectiva sócio-histórica de aprendizagem (VYGOSTKY,1991; 1993), e dialógica de linguagem (BAKHTIN, 1985a; 1985b; 1990; 2002); planejamento de propostas de açóes para o ensino de língua, com base nos fundamentos estudados e socialização das atividades desenvolvidas pelos professores participantes. A cada ano, as horas dedicadas ao estudo teórico foram progressivamente reduzidas e ampliadas as destinadas ao planejamento e à socialização.

No encaminhamento do trabalho com a produção de textos, nesse processo de formação, três momentos distintos ${ }^{3}$ possibilitam compreender o movimento realizado pela professora. Na etapa de 2001, a orientação para elaboração de projeto de ensino de língua portuguesa pelos professores seguiu o que a maioria dos livros didáticos propóe: a organização das aulas por eixos temáticos. $\mathrm{Na}$ etapa de 2002, iniciou-se a discussão acerca da organização do ensino de língua com base na perspectiva dos gêneros do discurso (BAKHTIN, 1985a) a partir da análise de práticas desenvolvidas pelos professores e socializadas a cada 
encontro. A compreensão de gêneros do discurso como critério para a organização curricular da disciplina de Língua Portuguesa - portanto, critério para elaboração do planejamento pelo professor (RODRIGUES, 2001), fundamentou a ação de formação e o planejamento de propostas de trabalho para o ensino de língua, em 2007.

Para a concretização deste estudo, discute-se inicialmente a constituiçáo do ser professor pela relaçáo que, historicamente, este estabelece com o conhecimento e a compreensão de que a construção de uma nova identidade do professor de português remete ao trabalho com o texto na sala de aula. Na sequência, apresentam-se três atividades de produção de textos desenvolvidas em sala de aula, representativas de momentos distintos da prática pedagógica de uma professora de Língua Portuguesa. Por fim, tecem-se algumas consideraçóes acerca do que distingue cada um desses momentos.

\section{O TRABALHO COM O TEXTO EM SALA DE AULA: A REAPROPRIAÇÃO DO PAPEL PRODUTIVO DE PROFESSORES E ALUNOS}

A compreensão de que o trabalho com a produção de textos deve se constituir "[...] no ponto de partida (e ponto de chegada) de todo o processo de ensino/aprendizagem da língua [...]". (GERALDI, 1993 , p. 135) vem fundamentando pesquisas e debates em eventos acadêmico-científicos da área, desde meados da década de 1980. Lopes-Rossi (2005) destaca, no entanto, que esse entendimento ainda é restrito fora dos meios acadêmicos. Para ela, em seu trabalho como formadora, "[...] os professores manifestam-se muito interessados no assunto, porém, carentes de fundamentação teórica e de exemplos práticos [...]". (LOPES-ROSSI, 2005, p. 80)

Entende-se, assim, que a formação continuada de professores assume um importante papel para o estabelecimento do diálogo entre as situaçóes conflituosas do cotidiano com o conhecimento. Nesse sentido, a formação continuada não pode ser entendida apenas como resultado de uma acumulação de conhecimentos pelos cursos que se faz, mas precisa 
ser assumida como trabalho de reflexão sobre a própria prática pedagógica, tendo em vista a (re)construção contínua da identidade profissional.

Para Geraldi (2010, p. 82), "[...] a relação com o conhecimento, mais do que a própria relação pedagógica, isto é, a relação com os aprendentes, desenhou os diferentes perfis de profissionais, cuja sequência constitui a história de nossa profissão [...]". Para este autor, o que torna alguém professor é a relação que, como profissional, estabelece com o conhecimento e essa relação passa por três momentos distintos que, no seu entender, permitem compreender a construção social e histórica das diferentes identidades do professor, que convivem e entrecruzam-se, sendo que cada uma ganha relevo numa determinada época histórica.

Da Antiguidade aos séculos XIV e XV não havia uma separação radical entre quem produzia o conhecimento e quem o ensinava. A partir do Mercantilismo, o professor não mais produzia o conhecimento, mas transmitia um saber que possuía, isto é, dominava o saber produzido por outros e o transmitia como conteúdo aos seus alunos. Inicia-se nesse período a necessidade de uma contínua atualização para saber o que se produz de novo. Essa identidade do professor permanece do século XVII até inícios do século XX. Na era tecnológica, o professor se define como aquele que aplica um conjunto de técnicas de controle na sala de aula. Nesse processo, delimita o tempo e a quantidade de exercícios, confere as respostas dos alunos com as do livro didático, marca o dia da verificação da aprendizagem. Entre outras atitudes, assume a de capataz de fábrica.

Para Nóvoa (1995), a exemplo de Geraldi, os professores limitaram-se a um saber disciplinar e se assumiram como transmissores de conhecimento em um dado momento da constituição histórica dessa profissão e, em outro, com a expansão da escola, dominar técnicas e procedimentos de ensino era o fundamental ao professor. As máximas - quem sabe faz, quem não sabe ensina e quem sabe faz, quem compreende ensina - decorrem do papel de repassadores de conhecimento e de aplicadores de técnicas, atribuído aos e assumido pelos professores.

Segundo Geraldi (2010), o modelo de professor que controla o processo de aprendizagem e o acesso à informação entra em crise nas duas últimas décadas do século XX. Para este autor, a construção de uma nova identidade para a docência pode estar na inversão da relação que 
professores e alunos estabelecem com o conhecimento, o que remete às noçóes de professor reflexivo e de professor pesquisador. Nóvoa (1995) também destaca a importância de os professores desenvolverem competências para contextualizar e reelaborar os conhecimentos que ensinam.

No caso do professor de Língua Portuguesa, a construção dessa nova identidade passa pelo trabalho com o texto em sala de aula.

Considerando o aluno e cada um deles em particular como sujeito leitor ou como sujeito autor de seus textos, ser professor já não pode mais ser o exercício puro e simples da capatazia (ou o exercício da gerência). É ser do aluno um interlocutor ou mediador entre o objeto de estudos (no caso, o texto) e a aprendizagem que se vai concretizando nas atividades de sala de aula. Cada um sendo um outro, portanto uma possível medida, o confronto dos pontos de vista faz da sala de aula um lugar de produção de sentidos. (GERALDI, 1993, p. 112)

Eleger o texto como unidade de ensino e aprendizagem da língua significa tomá-lo como lugar de encontro de sujeitos historicamente constituídos, ou seja, de sujeitos que têm o que dizer e para quem dizer, e têm razóes para fazê-lo e, por isso, escolhem estratégias que melhor permitem atingir os objetivos em cada situação de interação. (GERALDI, 1993) Em cada texto subjaz, portanto, um projeto de dizer - que é lhe singular - e é esse projeto de dizer que deve estar em jogo quando se propóe que professores e alunos se reapropriem do seu papel produtivo no ensino e aprendizagem da língua que se desenvolve na e pela escola, ou seja, para que de fato possam se constituir como sujeitos do seu dizer e do seu fazer.

Para Geraldi (2009, p. 3), “[...] introduzir o texto na sala de aula é introduzir a possibilidade das emergências dos imprevistos, dos acontecimentos, dos acasos [...]", porque

[...] o texto abre as portas para o inusitado, para o mundo da vida invadir a sala de aula, para o acontecimento conduzir a reflexão, sem que os sentidos se 
fechem nas leituras prévias e privilegiadas com que os textos têm sido silenciados quando presentes na sala de aula. (GERALDI, 2006, p. 27)

Isso implica, principalmente, devolver a palavra ao aluno para que ele se constitua sujeito do seu processo de aprendizagem, o que não quer dizer um nada fazer ou um nada a declarar por parte do professor, mas, acima de tudo, ser o outro nesse processo. Isso exige conhecimento e vontade de mudar. Mudanças exigem investimentos, estudo, posturas diferentes. Alguns professores já estão procurando trabalhar no sentido de assumirem a palavra, no planejamento de suas aulas, e de devolverem a palavra aos seus alunos e estes estão ocupando os espaços que, aos poucos, lhes são abertos. É o que se apresenta a seguir, na análise de três atividades de produção de textos, representativas de momentos distintos da prática pedagógica vivenciada por uma professora de Língua Portuguesa e, por conseguinte, por seus alunos.

\section{O TEXTO COMO PRÉ-TEXTO PARA O ENSINO DE GRAMÁTICA - PRIMEIRO MOMENTO}

\section{Caro Aluno!}

Observando a gravura, qual o fato que ela lhe sugere?

Organize um texto em que os verbos estejam no presente e no pretérito perfeito do indicativo.

O comando acima é a proposta de produção de texto apresentada pela professora Joana (nome fictício) a uma turma de $5^{\text {a }}$ série, de uma escola pública da rede estadual do município de Florianópolis ${ }^{4}$. Para esta atividade, a professora organizou a turma em grupos de três alunos e entregou a cada equipe uma figura para que, coletivamente, discutissem sobre o que esta lhes sugeria e, individualmente, escrevessem um texto seguindo um único critério: os verbos deveriam estar conjugados no presente e no pretérito perfeito do modo indicativo. Quando todos concluíram, alguns alunos socializaram suas produçóes e, na análise dos textos, a professora destacou o emprego dos verbos conforme o que havia solicitado. 
Considerando que para se produzir um texto, tal como propóe Geraldi (1993), é preciso que se tenha o que dizer, se tenha uma razão para dizer o que se tem a dizer, se tenha alguém para quem dizer o que se tem a dizer e assim se escolham as melhores estratégias para dizer o que se tem a dizer, a proposta elaborada pela professora não contempla aspectos importantes e intrínsecos a todo processo de escrita, pelo menos quando se entende e se assume que ler e escrever textos implica participar de uma relação interlocutiva, em que há sujeitos situados historicamente que assumem uma posiçáo em relaçáo ao seu dizer e ao dizer do outro.

Analisando a proposta em questão, pode-se dizer que a figura apresentada a cada grupo de alunos constitui a condição desencadeadora para a escrita do texto. Como os alunos têm uma tarefa a cumprir, eles buscam dizer o que a imagem que observam lhes suscita. Aqui, segundo Geraldi, realizam-se duas das condiçóes para se produzir um texto - ter o que dizer e ter razóes para dizer -, mas elas se anulam na medida em que não possibilitam a interlocução efetiva, ou seja, o diálogo das vozes expressas e manifestadas na palavra daquele que se assume como locutor e na contrapalavra de quem se assume como interlocutor (BAKHTIN, 1990, 2002), já que a razão para escrever o texto se limita ao cumprimento de uma tarefa escolar.

Pode-se dizer, também, que esta proposta exemplifica a reflexão de Geraldi (1993) sobre a perigosa entrada do texto em sala de aula: toma-se a produção do texto apenas como pré-texto para verificar se os alunos aprenderam aspectos da gramática estudados anteriormente. Nessa atividade, o que se propóe aos alunos é muito mais um exercício de escrita como treino para o emprego de tempos verbais do que a possibilidade de criar condiçóes para que os alunos aprendam a fazer uso da modalidade escrita da língua para efetivar um projeto discursivo.

\section{O TEXTO COMO ORGANIZAÇÃO DE SEQUÊNCIAS TEXTUAIS - SEGUNDO MOMENTO}

A Droga é um grave problema que afeta a humanidade. ${ }^{5}$

- Aprovar leis contra drogas.

- O fumo e as drogas. 
- Opiniāo do povo e dos proficionais [sic].

A população está se viciando com o fumo e drogas. A polícia já não dá mais conta. Tentar aprovar leis para proibir o uso de drogas náa leva a nada. Enquanto a comunidade náo se unir todos contra esse grave problema aumentará cada vez mais o vício das drogas.

As pessoas não se tocam que o fumo e as drogas fazem muito mal a [sic] saúde como, infarte [sic], problemas no pulmão, coração, etc. Quando começam [a] usar não conseguem mais parar, pois o vício das drogas já tomou conta do usuário.

Se cada um se conscientizar do mal que está fazendo a si próprio, bastaria. Seria um bom comę̧o para o fim desse problema.

O povo todo unido, e os proficionais [sic] (médicos) dando suas opiniöes, seria um bom exemplo, mas falar com firmeza, e de todo jeito, acabar com a publicidade de cigarros, bebidas alcólicas, [sic] entre outros.

As drogas não deveriam de existir no mundo, pois ela acaba com muitas vidas, mas como ela existe, e está se espalhando cada vez mais, devemos ter o máximo cuidado para não usar uma vez se quer, porque uma dose chama a outra.

(Texto de Opiniáo produzido por um grupo de alunos da $8^{a}$ série da Educação de Jovens e Adultos)

O texto transcrito acima representa o resultado de uma atividade de produçáo de "texto de opiniáo" planejada e desenvolvida pela professora Joana com alunos da Educação de Jovens e Adultos (EJA) em uma escola pública da rede de ensino do município a que ela se vinculava. A proposta de trabalho desta professora foi elaborada como parte das atividades do curso de formação continuada dos professores dessa rede de ensino no ano de 2002, conforme já apresentado ${ }^{6}$.

Para o trabalho com a argumentação, referida pelo aluno como "dissertação", nomenclatura também tradicionalmente empregada pela escola para definir o texto no qual predominam sequências da ordem do argumentar (DOLZ; NOVERRAZ; SCHNEUWLY, 2004), a professora planejou e desenvolveu as aulas com base no capítulo VIII - $O$ 
esquema básico da dissertação -, do livro Técnicas básicas de redação, de Branca Granatic (1995). Concluída a análise dos dois textos sugeridos nesta unidade do livro, a professora propôs a leitura do artigo de opinião O Brasil lê mal, de Cláudio de Moura Castro, da seção Ponto de vista, da revista Veja, de 06/03/2002. Os alunos receberam cópias do texto contendo todas as informaçóes que permitiam identificá-lo no que diz respeito à esfera de produção e de circulação deste gênero, entendidas como parte do enunciado (BAKHTIN, 1990; 1985a) na perspectiva de trabalho com os gêneros do discurso. Antes, porém, leram a notícia Phd propóe mudanças curriculares, publicada no jornal Diário Catarinense para conhecerem o articulista. Quando do relato desta atividade específica, no contexto do planejamento de trabalho para a produçáo escrita de um texto de opinião, a professora fez questão de enfatizar para os colegas do curso de formação (assim como o fez com seus alunos) que se tratava de outro "tipo de texto". No acento de valor (BAKHTIN, 2002) que atribui à notícia - outro tipo de texto -, a professora evidencia a noção de texto como atividade discursiva (BAKHTIN, 1985b), uma vez que ela está se referindo ao gênero, ou seja, à totalidade e a uma função que é própria da notícia.

A etapa seguinte foi a da produção de um "texto de opinião". Para tanto, os alunos foram organizados em grupos para definirem um tema sobre o qual opinar e realizarem pesquisas em relaçáo ao assunto escolhido. O texto a ser produzido deveria seguir o esquema estudado nas aulas anteriores: apresentação do tema e de três argumentos, desenvolvimento dos argumentos e conclusão. É interessante ressaltar que, mesmo tendo percebido que o texto $O$ Brasil lê mal não se adequava ao esquema textual estudado, a atividade de produção seguiu essa orientação.

Ainda que na proposta de produção de texto, a professora volte ao esquema da dissertação, fundamentando seu trabalho em uma visão imanente de texto, entende-se que no conjunto de sua prática pedagógica nesta proposta de trabalho evidencia-se a compreensão de que o texto se constitui na unidade de ensino da língua e de que este ensino, metodologicamente, deve se organizar a partir das práticas de uso da própria língua.

Pelo trabalho realizado com textos de opiniâo, entende-se que a professora começa a assumir uma postura de quem concorda que o tex- 
to se constitui na possibilidade de professores e alunos se reapropriarem de seu papel produtivo no ensino-aprendizagem da língua. (GERALDI, 1993) Aqueles, quando planejam e elaboram sua aula a partir de textos que circulam socialmente e não seguem apenas o que já está predeterminado no livro didático, e estes, quando têm a possibilidade de assumir a palavra porque têm o que dizer, para quem dizer e escolhem as estratégias para o sucesso de seu projeto discursivo.

\section{A REAPROPRIAÇÃO DO PAPEL PRODUTIVO DE PROFESSORES E ALUNOS - TERCEIRO MOMENTO}

Agora é a sua vez de escrever:

Escolha outras "coisas" para seu poema, diferentes das apontadas no poema de Maria Dinorah, como por exemplo: coisas bonitas, coisas feias, coisas alegres, coisas tristes, coisas de rir, coisas de chorar ...

Enumere as "coisas" nos segundo e terceiro versos de cada estrofe, como no poema lido; procure escolher palavras que comecem com o mesmo som para dar ritmo aos versos.

O comando acima refere-se ao terceiro momento do trabalho com produção de textos na prática de Joana, tendo em vista a reapropriação do seu papel produtivo (GERALDI, 1993) no ensino-aprendizagem de língua. Esta proposta de trabalho corresponde à segunda atividade de produção de texto planejada e desenvolvida com alunos de $6^{a}$ série, de uma escola da rede municipal de ensino, no contexto do projeto Encontro com a poesia, elaborado por esta professora juntamente com mais três colegas no processo de formação continuada de 2007, já referido na seção inicial deste trabalho.

O projeto em questão foi organizado em três etapas distintas: Mergulhando no mundo da poesia, Tecendo poemas e Divulgando nosso trabalho. Na turma da $\sigma^{\mathrm{a}}$ série da professora Joana, o desenvolvimento do trabalho, com o gênero poema, iniciou-se com a apresentação da proposta de modo que, ao mergulharem no mundo da poesia, já sabiam que os textos a serem produzidos seriam apresentados em um Sarau Lite- 
rário para a comunidade escolar. Antes mesmo de iniciarem o estudo do poema, os alunos já tinham razóes para escrever e tinham interlocutores a quem escrever. Faltava, então, ter o que dizer e escolher as melhores estratégias. Com o objetivo de subsidiar os alunos para esta tarefa, foram planejadas e realizadas diferentes atividades, metodologicamente organizadas a partir das práticas de uso da língua, quais sejam: falar, ouvir, ler, escrever e refletir sobre os usos da língua.

Para possibilitar o contato com o gênero a ser estudado, a professora selecionou e disponibilizou poemas de diferentes autores que foram lidos pelos alunos. Depois da primeira imersão nesse universo pela leitura-fruição (GERALDI, 1993) de poemas, foi organizado um mural com poemas lidos e transcritos pelos alunos. Na leitura e análise dos textos eram relembradas características do gênero como o sentido conotativo e denotativo das palavras, foram introduzidos os conceitos de linguagem figurada e de intertextualidade. A primeira etapa do projeto também foi marcada pela aproximação dos alunos com o gênero biografia. Depois de pesquisarem aspectos da vida e da obra de diferentes autores, os alunos escolheram um deles para escrever sua biografia e apresentá-la oralmente em sala de aula.

Concluída a etapa de imersão no mundo da poesia, era o momento de iniciar a escrita de poemas pelos alunos. Como esta etapa constituía-se fundamentalmente pela produção de poemas, além do aprofundamento e do estudo sistemático de alguns aspectos do gênero, pela leitura-estudo (GERALDI, 1993) de diferentes poemas, foram também propostas diferentes atividades de escrita e reescrita dos textos produzidos. Uma delas é a que está transcrita na abertura desta seção e foi planejada a partir da leitura e análise do poema Coisas, de Maria Dinorah. Os poemas produzidos nesta etapa foram apresentados, por eles mesmos, em um Sarau Literário para toda a comunidade escolar.

O trabalho com a produção de textos realizado pela professora Joana no terceiro momento de sua prática pedagógica, analisado neste trabalho, se distingue significativamente do que ocorreu nos dois momentos anteriores. Observe-se que o primeiro contato dos alunos com os poemas - gênero em estudo no terceiro momento - se dá pela própria leitura do gênero. A professora organiza suas aulas a partir de três etapas distintas, uma delas dedicada à leitura de poemas, o que denota a per- 
cepção de que a melhor forma de ensinar o conhecimento dos meandros implicados na leitura e na produção de um texto é o próprio contato com o texto. Só depois de lerem, analisarem e socializarem sua aprendizagem sobre a leitura de poemas é que os alunos começam a se dedicar à escrita.

Ganha relevância nesse processo a relação com o outro, pela divulgação de tudo o que é produzido: o mural de poemas no pátio da escola, a apresentação da biografia e do poema de um determinado autor aos colegas e, principalmente, a apresentação dos próprios poemas em sarau literário. Essa etapa já estava prevista quando da apresentação do projeto de trabalho aos alunos. Desde o início do desenvolvimento dessa proposta de trabalho, eles sabiam que teriam interlocutores para o seu texto. Os textos dos alunos ganharam auditórios muito mais amplos do que o espaço físico no qual foram elaborados e declamados. Eles se constituíram como enunciados e, como tal, elos na ininterrupta cadeia da interação verbal. (BAKHTIN, 1990)

Cabe ressaltar, no entanto, que nesse terceiro momento de trabalho com o texto ainda se evidenciaram muitas atividades nas quais o foco foi tão somente a forma de composição do texto, em uma perspectiva estritamente linguística ou formal, na qual a ênfase recaiu sobre a construção dos versos, das rimas, de palavras cujo sentido é denotativo e conotativo, mas sem se ter a preocupação com o efeito de sentido que uma forma ou outra de compor o texto provoca no leitor. Ainda assim, é possível dizer que a dimensão discursiva se fez presente (e de forma significativa) no desenvolvimento do trabalho dessa professora, tanto na escolha dos textos propostos para leitura, como na leitura que ela fez dos textos dos alunos.

\section{CONSIDERAÇÕES FINAIS}

Uma vez apresentadas cenas que representam três momentos da prática pedagógica de Joana na reapropriação de seu papel produtivo (e também do papel produtivo de seus alunos) no ensino e aprendizagem da língua, particularmente da escrita de textos, algumas consideraçóes se fazem necessárias. No primeiro momento aqui analisado, o objetivo da produção de textos pelos alunos foi o de verificar a aprendizagem do em- 
prego dos tempos verbais, que foram tomados apenas como unidades da língua, desconsiderando-se a relaçáo de temporalidade que estabelecem com o momento da enunciação e com o ponto de vista do locutor em relação ao seu dizer. Ainda assim, entende-se que o texto assume, em alguma medida, a condição de unidade para o ensino e a aprendizagem da língua, mas no trabalho que a professora desenvolve com a produção de textos, este - o texto - se limita a pré-texto para o ensino da gramática.

Quando propõe a escrita de textos de opinião, segundo momento analisado, a professora foge à tipologia tradicional na medida em que não solicita aos alunos que leiam e escrevam uma narração, uma descrição ou uma dissertação. Apesar disso, o trabalho ainda se limita ao esquema da dissertação, portanto, a uma visão imanente do texto, não avançando muito para a compreensão de aspectos da dimensáo social, elemento constitutivo dos textos, quando entendidos como enunciados, tal como propóe Rodrigues (2001), com base na concepção de gêneros do discurso, na visão bakhtiniana. (BAKHTIN, 1985a)

A prática pedagógica planejada e desenvolvida por esta professora, neste segundo momento, reflete e refrata o que vinha se efetivando na ação de formação continuada: o estudo e a discussão sobre o trabalho com o texto, a partir da perspectiva dos gêneros do discurso, estavam apenas iniciando e se realizavam apenas no plano teórico. Não se estava possibilitando aos professores a visualização de como realizar em sala de aula este trabalho, tal como apontou Lopes-Rossi (2005). A professora buscou, então, referências nos materiais de que dispunha e na sua própria experiência. Para o trabalho com o poema, a professora planeja e organiza sua ação didática a partir de três grandes etapas, e em cada uma delas há outras, de modo que os alunos vão se apropriando da dimensão discursiva e da dimensão linguística do gênero em estudo pelo próprio diálogo que estabelecem com textos os mais diversos. Desde o princípio do trabalho, os alunos são envolvidos nas situaçóes de produção desse gênero do discurso, quer pelo conhecimento do autor, quer pelo reconhecimento dos sentidos que evoca no leitor a leitura de um poema, ao mesmo tempo em que as vivenciam quando assumem a palavra para falar de coisas bonitas, coisas feias, coisas alegres, coisas tristes, coisas de rir, coisas de chorar, a exemplo do que fez Maria Dinorah no poema que leram. Ao terem a oportunidade de dar uma entoação própria a essas 
palavras e ao expressarem suas escolhas no Sarau Literário constituem-se autores de seu próprio projeto de dizer. $\mathrm{Na}$ análise deste momento da prática da professora, fica evidenciada a presença do texto como possibilidade de professores e alunos se reapropriarem de seu papel produtivo no ensino e aprendizagem da língua, ou seja, de ambos constituírem-se autores de seu dizer.

Observam-se significativas mudanças no trabalho com o texto como unidade de ensino da aula de Língua Portuguesa nos três momentos aqui analisados. $\mathrm{O}$ que diferencia um e outro é o conceito de texto que a professora assume e a forma de abordagem que ela faz do texto nas atividades de escrita planejadas, objeto de nossa análise: no primeiro momento, o texto é tomado como pré-texto para o ensino de gramática; no segundo momento, a proposta de produção de um texto de opinião limita-o à sua forma de composição, ou seja, à organização do uso escolar de textos de opinião; no terceiro momento, evidencia-se a preocupação com a abordagem da dimensão social do gênero, implicando necessariamente a relação autor-leitor e o espaço de circulação.

As atividades de produçáo de textos planejadas e desenvolvidas por Joana, representativas de três momentos distintos de sua ação docente, evidenciam a compreensão responsiva ativa desta mesma professora às ações de formação continuada. Há de se considerar que, na ação de ensinar e aprender que se desenvolve em um curso de formação continuada de professores, interagem os professores e o formador, e os próprios termos da teoria dialógica da linguagem que a fundamenta. Nesse processo de aprendizado, não existe um progresso em linha reta, ou simplesmente acúmulo de conhecimento; há uma paulatina reestruturação interior, que projeta novos fazeres. Como afirma Furlanetto (2007), a passagem da teoria à prática náo pode ser idealizada e nem imposta aos professores; precisa ser resultado de um processo que produz aprendizado.

Assim como a relação entre teoria e prática resulta de um complexo processo que envolve a ação docente, a reflexão sobre esta ação, tendo em vista uma nova ação, a relação entre formação continuada e prática docente não pode ser compreendida como um processo que se viabiliza como via de mão única. Dizendo de outro modo: em um processo de formação continuada estáo implicados aspectos que ultrapassam a apropriação do conhecimento teórico-metodológico acerca do objeto 
de conhecimento de uma determinada área, como o ensino de língua portuguesa, e sua aplicação na prática docente pelo cursista. Pode-se pensar, por exemplo, nas relaçóes que se estabelecem entre formador e professores, nas condiçôes de trabalho para efetivar as açôes em estudo, nas relaçóes que se estabelecem no contexto da própria escola (do professor cursista com seus pares e com os alunos, dos alunos ente si) para a efetivação das açôes planejadas, nas relaçóes que se estabelecem nas diferentes esferas sociais das quais se participa. É nessa complexa rede de relaçóes que o professor forma a si mesmo e forma o outro, aprende e ensina sobre o objeto de conhecimento com o qual trabalha e sobre o seu ensino, sobre a docência.

Mesmo considerando que não é apenas no contexto de espaços e momentos específicos que se viabiliza a formação de um professor, o trabalho aqui analisado indica que a formação continuada pode contribuir para que se construam outras realidades para o ensino e a aprendizagem da Língua Portuguesa na e pela escola, na medida em que os professores sempre assumem uma atitude valorativa em relação ao seu próprio processo de formação, quer seja ela de indiferença, de reflexão sobre sua prática ou de mudança de atitude.

Ainda que não se possa generalizar, este trabalho é representativo do processo de reapropriação do papel produtivo de professores e alunos, ou seja, de que pelo trabalho com o texto em sala de aula é possível a ambos constituírem-se sujeitos do seu dizer, portanto autores. A compreensão de como se realiza a assimilação da palavra de outrem no processo de formação ideológica do homem possibilita a compreensão de que se constituir autor é assumir uma posição no contexto das vozes sociais.

\section{REFERÊNCIAS}

BAKHTIN, M. Questôes de literatura e estética: a teoria do romance. 5. ed. São Paulo: Hucitec, 2002. citec, 1990.

. (Voloshinov). Marxismo e filosofia da linguagem. 5. ed. São Paulo: Hu- 
BAKHTIN, M. El problema de los géneros discursivos. In: BAKHTIN, M. Estética de la creación verbal. 2. ed. México: Siglo Veintiuno, 1985a, p. 248-293. . El problema del texto en la lingüística, la filología y las otras ciencias humanas. In: BAKHTIN, M. Estética de la creación verbal. 2. ed. México: Siglo Veintiuno, 1985b, p. 248-293.

DOLZ, J.; NOVERRAZ, M.; SCHNEUWLY, B. Sequências didáticas para o oral e a escrita: apresentação de um procedimento. In: ROJO, R. (Org.). Gêneros orais e escritos na escola. Campinas: Mercado de Letras, 2004, p. 215-246.

FURLANETTO, M. M. Práticas discursivas: desafio no ensino de Língua Portuguesa. In: CORREA, D. A.; SALEH, P. B. de O. (Org.). Práticas de letramento no ensino: leitura, escrita e discurso. São Paulo: Parábola Editorial; Ponta Grossa: UEPG, 2007.

GERALDI, J. W. A aula como acontecimento. São Carlos: Pedro \& João Editores, 2010.

A presença do texto na sala de aula. In: LARA, G. M. P. (Org.). Lingua(gem), texto, discurso: entre a reflexão e a prática. Rio de Janeiro: Lucerna; Belo Horizonte: FALE/UFMG, 2006. v. 1. p. 13-29.

. Portos de Passagem. 2. ed. Sáo Paulo: Martins Fontes, 1993.

LOPES-ROSSI, M. A. G. Gêneros discursivos no ensino de leitura e produção de textos. In: KARWOSKI, A. M.; GAYDECZKA, B.; BRITO, K. S. (Orgs.). Gêneros textuais: reflexôes e ensino. Palmas, PR: Kaygangue, 2005, p. 79-93.

NÓVOA, A. Diz-me como ensinas, dir-te-ei quem és e vice-versa. In: FAZENDA, I. (Org.). A pesquisa em educaçâo e as transformaçóes do conhecimento. Campinas: Papirus, 1995.

RODRIGUES, R. H. A constituiçäo e o funcionamento do gênero jornalístico artigo: cronotopo e dialogismo. 2001. 347f. Tese (Doutorado em Linguística Aplicada e Estudos da Linguagem). Programa de Estudos Pós-graduados em Linguística Aplicada e Estudos da Linguagem (LAEL), Pontifícia Universidade Católica de São Paulo, São Paulo, 2001.

VYGOTSKY, L. S. Pensamento e Linguagem. 3. ed. São Paulo: Martins Fontes, 1993. . A formação social da mente. 4. ed. São Paulo: Martins Fontes, 1991. 


\section{NOTAS}

1. Este artigo inédito consiste na reelaboração do trabalho apresentado como requisito parcial para o concurso de Professor Adjunto I, do campo de conhecimento: Metodologia e Prática de Ensino de Língua Portuguesa e Literatura, do Departamento de Metodologia do Ensino, da Universidade Federal de Santa Catarina. Agradeço as contribuiçóes de Raquel Salek Fiad, Clécio Bunzen e Émerson de Pietri, membros da banca, e a leitura atenta e as sugestôes de Maria Marta Furlanetto.

2. A exceçấo foi a etapa de 2000 , dedicada à escrita do documento orientador por um grupo de trabalho formado por representantes do conjunto de professores de Língua Portuguesa desta rede de ensino.

3. São retomados apenas três dos cinco momentos, porque no ano de 1999 a professora náo integrava o grupo de professores desta rede de ensino e no ano de 2000 a formação foi organizada com base em um objetivo muito específico, como indicado em nota anterior.

4. Neste período, a professora atuava em uma escola da rede estadual de ensino. O primeiro momento da prática desta professora, analisado nesta seção, corresponde ao período anterior a sua participação no processo de formação apresentado na seção inicial deste artigo. Em 2001 ela passa a integrar a rede municipal de ensino, cuja secretaria de educação organizou e se responsabilizou pela efetivaçáo desta ação de formação continuada.

5. O texto é a transcrição literal do que foi produzido pelos alunos.

6. Além de responder ao desafio de elaboração de uma proposta de trabalho de produção de textos, com base na perspectiva dos gêneros do discurso, no seu relato, a professora destacou que a atividade também foi planejada em função de uma situação-problema apresentada por um dos alunos, que se inscreveu para os exames supletivos e precisava saber o que era narração, descrição e dissertação. Considerando essa necessidade, a professora planejou um conjunto de $10 \mathrm{~h} / \mathrm{a}$, das quais se sintetiza as que tiveram por objetivo a produçấo de um texto de opinião.

Recebido em 06 de março de 2015. Aprovado em 11 de maio de 2015.

DOI: http://dx.doi.org/10.1590/CC0101-32622015146738 